\title{
A Movable Test System for Thermal Performance of Domestic Solar Water Heating System and Its Uncertainty Analysis
}

\author{
YANG Liangen ${ }^{1, \mathrm{a}}, \mathrm{CAO}$ Haifeng ${ }^{1, \mathrm{~b}}$, HE Tao ${ }^{1, \mathrm{c}}$, CHENG Jiabao ${ }^{1, \mathrm{~d}}$ \\ ${ }^{1}$ Hubei University of Technology, Hubei Wuhan,430068, China \\ ayanglg@hbut.edu.cn, ${ }^{\mathrm{b}} 454559775 @ q q . c o m,{ }^{\mathrm{c}}$ hetao_wh@163.com, ${ }^{\mathrm{d}} 411202142 @$ qq.com
}

Keywords: movable; thermal performance test; uncertainty analysis; domestic solar water heating system.

\begin{abstract}
A movable test system for thermal performance of domestic solar water heating system is proposed to solve the problem that fixed test system has low utilization efficiency of climatic resources. The test system consists of a bus body, closed pipeline system, measurement and control system for temperature and flow, mobile electric cabinet, etc.. The temperature and flow in thermal performance test can be controlled respectively in $-0.2{ }^{\circ} \mathrm{C} \sim+0.2{ }^{\circ} \mathrm{C}$. The mathematic model of daily useful energy of the test system has been established. By analyzing measurement uncertainty components of daily useful energy, its relative expanded uncertainty is $3.2 \%$. The movable system can make full use of climate resources of different geographical areas and improve test efficiency.
\end{abstract}

\section{Introduction}

At present thermal performance test for domestic solar water heating systems and solar collectors at home and abroad is conducted by using fixed test system. But when the weather is cloudy or high winds, test conditions such as solar irradiance, environment temperature and wind speed may not meet the test requirements specified in GB/T18708-2002. In this case, thermal performance test will not be conducted ${ }^{[1]}$. As a result, testing capacity for domestic solar water heating systems and solar collectors can't meet the demand of our country. There is a urgent need to develop a kind of movable thermal performance test system for domestic solar water heating systems and solar collectors in order to make full use of the climate conditions in different geographical areas, increase test days and improve the test capacity. A movable thermal performance test system for domestic solar water heating systems and solar collectors proposed in this paper is a vehicular test system and its test system is installed in a medium bus. 17 seats of the bus have been removed. Therefore, it can conduct thermal performance test in any place which meets climate conditions specified in GB/T18708-2002. Limited by paper length, this paper mainly discusses the thermal performance test system for domestic solar water heating system.

\section{Working Principles of the Test System}

The movable test system for thermal performance consists of four parts: bus body, closed pipeline system, measurement and control system for temperature and flow, mobile electric cabinet. The measurement and control system for temperature and flow, closed pipeline system are integrated in the bus. The bus is separated into three parts: driving, preparation and equipment rooms.

The principle of the closed cycle pipe system of the test system is shown in Fig.1. It can be divided into two parts by a plate heat exchanger ${ }^{[2]}$. One which is used to control initial temperature control in the test of daily useful energy consists of the plate heat exchanger and water chiller, heater, pump, expansion tank, etc. in the bus. The other includes heater, pump and plate heat exchanger and is used to control initial and final temperature. $T o_{2}, T_{i 2}$ and $T s_{2}$ are respectively water temperature of the outlet of the storage tank, plate heat exchanger inlet and inner of the storage tank. Because the plate exchanger outlet and storage tank inlet is separated only a three-way valve, $\mathrm{Ti}_{2}$ can be considered as the inlet water temperature of storage tank. Temperature $T_{2}, T_{2}$ and $T s_{2}$ are measured by Pt resistance temperature sensor. All pipes are wrapped by heat preservation material 
in order to prevent environment temperature influence on the test system. Before the test, the medium bus installed the test system is driven to a predetermined test site. After the mobile electric cabinet is removed, water inlet and outlet in electric cabinet are respectively connected to the inlet and outlet of bus, test parameters are set up, we can start test.

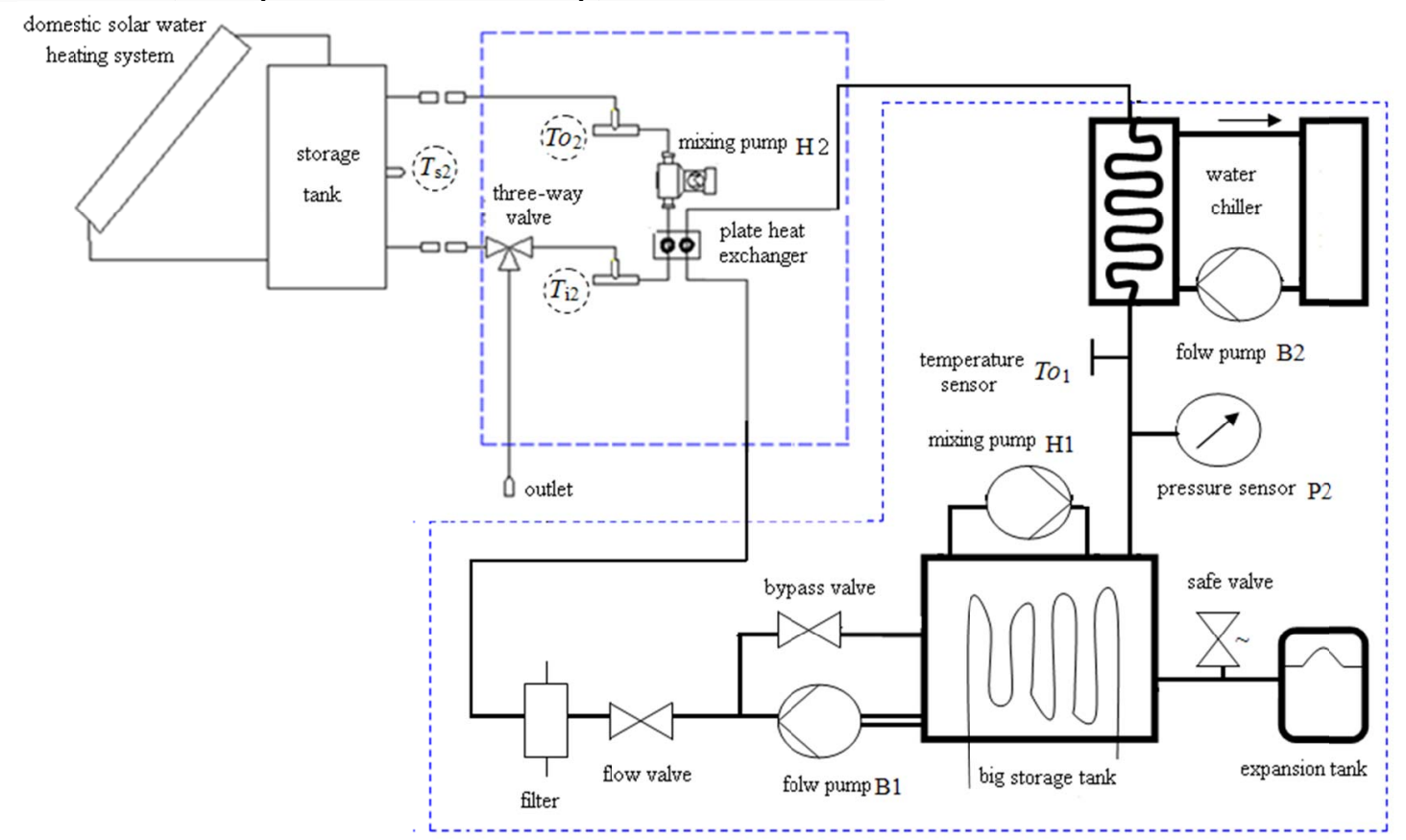

Fig. 1 principle of the closed cycle pipe system

The test system can measure "daily useful energy" and "average heat loss factor" according to requirements of thermal performance specified in GB/T18708 《Test methods for thermal performance of domestic solar water heating systems》 and GB/T19141 《Specification of domestic solar water heating systems $》$. Working medium flow should be controlled in $400 \mathrm{l} / \mathrm{h} \sim 600 \mathrm{l} / \mathrm{h}$ and temperature variation in inlet of storage tank should be controlled within $-0.2{ }^{\circ} \mathrm{C} \sim+0.2{ }^{\circ} \mathrm{C}$.

GB/T 18708 specifies that thermal performance test of domestic solar water heating systems should include at least round-the-clock outdoor test of four days for the whole system and overnight heat loss test to determine heat loss coefficient of storage tank. System test of every day should be conducted in outdoors.

Principle of data acquisition and electrical control of the test system is shown in Fig. 2 and it adopts working mode based on PCI bus ${ }^{[3]}$. It consists of various sensors and actuators, PCI - 1710 card with 16 channel A/D and 2 D/A, PCI - 1730 card with 32 channel digital input/output, etc.. Data from various sensors, conditions are real-time acquired through data acquisition channels and used to control operation of test system through output after processed by computer program.

Control method for system temperature is as follows. Before test starts, collector must be covered with sunshade in order to avoid direct sunlight which affects the initial temperature of control system. Water is pumped into the storage tank until water flow out of the overflow opening on the tank. Pump H2 is turned on for mixing water and make it in circulation at $400 \mathrm{~L} / \mathrm{h} \sim 600 \mathrm{~L} / \mathrm{h}$ so as to make the temperature in the whole system no difference. Simultaneously, prespecified temperature can be reached through heat exchange between the plate heat exchanger and the circle pipe in the bus. When the temperature at the inlet of the storage tank varies $< \pm 1^{\circ} \mathrm{C}$ in 5 min at least, control for initial temperature can be regarded as finish and the test system has reached the predetermined temperature $t_{\mathrm{b}}$. We should record the temperature, stop circulation and remove the sunshade. 


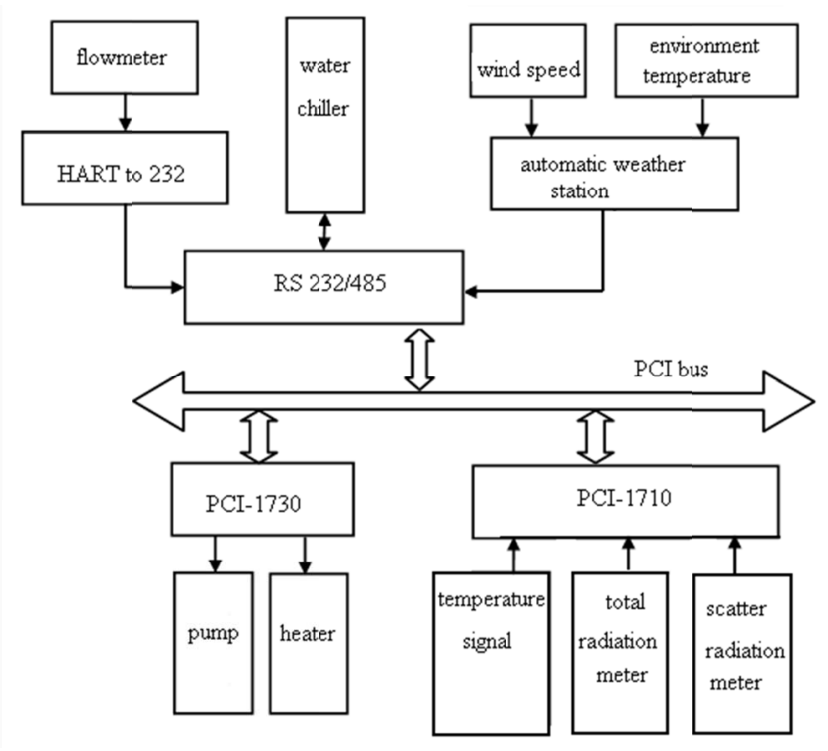

Fig. 2 diagram of data acquisition and electric control

The test system uses mixing method for daily useful energy and should work 8 hours which includes $4 \mathrm{~h}$ before and $4 \mathrm{~h}$ after the sun at high noon. After $8 \mathrm{~h}$ test, collector of domestic solar water heating system should be covered and start water circle with $400 \mathrm{~L} / \mathrm{h} \sim 600 \mathrm{~L} / \mathrm{h}$. Water in the bottom of the storage tank is pumped to the top of the tank in order to make water temperature uniform. When variation of $T_{\mathrm{i} 2}$ in $5 \mathrm{~min}$ doesn't exceed $\pm 0.2^{\circ} \mathrm{C}$, the test system can be regarded as steady and $t_{e}$ of the storage tank should be recorded.

\section{Design of system software}

Software of the test system is based on software architecture model of LabVIEW state machine and the data collection and control of temperature and flow is realized through graphical function module. According to test procedures of daily useful energy and average heat loss factor, total test conditions are divided into start, initialization, test selection (daily useful energy or average heat loss factor), temperature control (including mixing water, heating, judgment), test timing, test results computation and test end, etc.. The division is not only can make the test process smoothly, but also cannot interfere with each other, and the test process can be displayed in real time. As a result, the test system can realize functions such as automatic judgment, data acquisition and processing.

\section{Test verification for test system performance}

Two domestic solar heating system of same close-coupled collector storage model which are produced within same process and same production shift are used for comparison samples and tested respectively in the same time by a calibrated fixed test system and the movable test system. $\mathrm{GB} / \mathrm{T} 19141$ specifies water temperature at the end of the storage tank collecting heat $t_{\mathrm{e}} \geq 45^{\circ} \mathrm{C}$, daily useful energy per contour aperture area of domestic solar water heating system $q \geq 7.7 \mathrm{MJ} / \mathrm{m}^{2}$ and average heat loss factor $U_{\mathrm{SL}} \leq 16 \mathrm{~W} /\left(\mathrm{m}^{3} \cdot \mathrm{K}\right)$ when solar irradiation $H=17 \mathrm{MJ} / \mathrm{m}^{2}$. Comparison test results are shown in Tab.1. The test results from the test system are in good agreement with that from the fixed system. From initial temperature, the temperature control effect of the movable test system is better than that of the fixed system. 
Tab. 1 results of comparison test

\begin{tabular}{|c|c|c|}
\hline $\begin{array}{c}\text { Test } \\
\text { items }\end{array}$ & calibrated fixed test system & movable test system \\
\hline $\begin{array}{l}\text { daily } \\
\text { useful } \\
\text { energy }\end{array}$ & $\begin{array}{c}t_{\mathrm{e}}=48.811^{\circ} \mathrm{C} \quad q=8.23\left[\mathrm{MJ} / \mathrm{m}^{2}\right] \\
\text { (initial temperature: } 19.53\left[{ }^{\circ} \mathrm{C}\right] ; \\
\text { environment temperature: } 29.79\left[{ }^{\circ} \mathrm{C}\right] \text {; } \\
\text { solar irradiation: } 18.52\left[\mathrm{MJ} / \mathrm{m}^{2}\right] \text { ) }\end{array}$ & $\begin{array}{c}t_{\mathrm{e}}=47.39{ }^{\circ} \mathrm{C} \quad q=8.27\left[\mathrm{MJ} / \mathrm{m}^{2}\right] \\
\text { (initial temperature: } 19.94\left[{ }^{\circ} \mathrm{C}\right] ; \\
\text { environment temperature: } 29.70\left[{ }^{\circ} \mathrm{C}\right] ; \\
\left.\text { solar irradiation: } 18.51\left[\mathrm{MJ} / \mathrm{m}^{2}\right)\right]\end{array}$ \\
\hline $\begin{array}{l}\text { average } \\
\text { heat loss } \\
\text { factor }\end{array}$ & $\begin{array}{c}U_{\mathrm{SL}}=11.9\left[\mathrm{~W} /\left(\mathrm{m}^{3} \cdot \mathrm{K}\right)\right. \\
\text { (environment temperature: } 24.79\left[{ }^{\circ} \mathrm{C}\right] ; \\
\text { wind speed: } 2.2[\mathrm{~m} / \mathrm{s}] \text { ) }\end{array}$ & $\begin{array}{c}U_{\mathrm{SL}}=12.3\left[\mathrm{~W} /\left(\mathrm{m}^{3} \cdot \mathrm{K}\right)\right] \\
\text { (environment temperature: } 24.54\left[{ }^{\circ} \mathrm{C}\right] ; \\
\text { wind speed: } 2.5[\mathrm{~m} / \mathrm{s}] \text { ) }\end{array}$ \\
\hline
\end{tabular}

\section{Uncertainty analysis of the test system}

Main factors affecting on uncertainty of the test system include solar irradiation, environment temperature, working medium temperature and aperture area, etc.. Due to paper space limitations, measurement uncertainty of daily useful energy is only analyzed in the paper. Test object used in uncertainty analysis is mentioned above. Storage tank capacity $m=110.50 \mathrm{~kg}$, contour aperture area $A_{\mathrm{c}}=1.928 \mathrm{~m}^{2}$. Test parameters by measurement are as follows.

a) Water temperature in storage tank at the start and the end of collecting hot test are respectively $19.96{ }^{\circ} \mathrm{C}$ and $57.76{ }^{\circ} \mathrm{C}$.

b) Daily solar irradiation $H$ is $19.045 \mathrm{MJ} / \mathrm{m}^{2}$.

Calculation for uncertainty of daily useful energy. The mathematic model of daily useful energy of the test system is established as Eq.1.

$$
\mathrm{Q}_{\mathrm{s}}(e)=17 \times \frac{c_{p w} m\left(t_{e}-t_{b}\right)}{10^{6} A_{c} H}
$$

Where $C_{\mathrm{pw}}$ is specific heat capacity of water. $t_{\mathrm{e}}$ and $t_{\mathrm{b}}$ are respectively water temperature in storage tank at the start and the end of collecting hot test.

By the formula (1), combined standard uncertainty of daily useful energy $Q_{\mathrm{s}}$ expressed by relative uncertainty can be determined as follows.

$$
u_{c}^{2}\left(Q_{s}\right)=u^{2}(m)+u^{2}(\Delta t)+u^{2}\left(A_{c}\right)+u^{2}(H)
$$

Where $\Delta t=t_{\mathrm{e}}-t_{\mathrm{b}} . u(m), u(\Delta t), u\left(A_{c}\right), u(H)$ are respectively standard uncertainty of $m, \Delta t, A_{\mathrm{c}}$ and $H$. Their assessment methods are shown in Tab.2.

Tab. 2 summary table of uncertainty

\begin{tabular}{c|c|c}
\hline $\begin{array}{c}\text { standard uncertainty } \\
\text { components }\end{array}$ & uncertainty sources & assessment methods \\
\hline$u_{m}$ & storage tank capacity & class A; class B \\
\hline$u_{A_{c}}$ & contour aperture area & class A; class B \\
\hline$u_{\Delta t}$ & temperature rise in storage tank & class $\mathrm{c}$ \\
\hline$u_{H}$ & solar irradiance & class \\
\hline
\end{tabular}

The measurement standard uncertainty of storage tank capacity. Storage tank capacity $m$ can be obtained by 6 times weighing.

$$
m=m_{1}+m_{2}+m_{3}+m_{4}+m_{5}+m_{6}
$$

Their transform coefficients are calculated according to Eq. 4 .

$$
c_{m}=\partial(m) / \partial\left(m_{i}\right)=1 \quad i=1,2, \ldots, 6
$$

Through 10 times repeated measurement results (data is omitted in the paper), standard uncertainty of $m$ can be estimated according to Eq.5. $u(m)=0.25 \mathrm{~kg}$.

$$
u\left(X_{i}\right)=\sqrt{\sum\left(X_{i}-X\right)^{2} /(n-1)}
$$


According to the verification certificate of electronic balance, the maximum error of indication at (5-20) $\mathrm{kg}$ position is $\pm 0.01 \mathrm{~kg}$. Therefore,

$$
u\left(m_{i}\right)=0.01 / \sqrt{3}=0.0058 \mathrm{~kg}
$$

According to transform coefficient computed in Eq.4, measurement uncertainty components of storage tank capacity $m$ are shown in Tab.3.

Tab. 3 measurement uncertainty components of $m$

\begin{tabular}{c|c|c|l|c|c}
\hline $\begin{array}{c}\text { input } \\
\text { quantity }\end{array}$ & $\begin{array}{c}\text { estimated } \\
\text { value } \\
{[\mathrm{kg}]}\end{array}$ & $\begin{array}{c}\text { standard } \\
\text { uncertainty } \\
{[\mathrm{kg}]}\end{array}$ & $\begin{array}{c}\text { distribution } \\
\text { type }\end{array}$ & $\begin{array}{c}\text { transform } \\
\text { coefficent }\end{array}$ & $\begin{array}{c}\text { uncertainty } \\
\text { components } \\
{[\mathrm{kg}]}\end{array}$ \\
\hline$m$ & 110.50 & 0.25 & normal & 1.000 & 0.25 \\
\hline$m_{1}$ & 19.23 & 0.0058 & rectangular & 1.000 & 0.0058 \\
\hline$m_{2}$ & 19.20 & 0.0058 & rectangular & 1.000 & 0.0058 \\
\hline$m_{3}$ & 19.18 & 0.0058 & rectangular & 1.000 & 0.0058 \\
\hline$m_{4}$ & 19.14 & 0.0058 & rectangular & 1.000 & 0.0058 \\
\hline$m_{5}$ & 19.19 & 0.0058 & rectangular & 1.000 & 0.0058 \\
\hline$m_{6}$ & 14.56 & 0.0058 & rectangular & 1.000 & 0.0058 \\
\hline
\end{tabular}

The standard uncertainty $u_{\mathrm{m}}$ of $m$ is

$$
u_{m}=\sqrt{u^{2}(m)+\left[c_{1} u\left(m_{1}\right)+c_{2} u\left(m_{2}\right)+\cdots \cdots+c_{6} u\left(m_{6}\right)\right]^{2}} \approx 0.25 \mathrm{~kg}
$$

The relative standard uncertainty of $m$ is

$$
u_{r e l}(m)=\frac{u_{m}}{m} \approx 0.23 \%
$$

The measurement standard uncertainty of contour aperture area $\boldsymbol{A}_{\mathrm{c}}$. Mathematic model of contour aperture area is

$$
A_{c}=L \times W
$$

From 10 times repeated measurement results of $L$ and $W, u\left(A_{\mathrm{c})}\right.$ is

$$
u\left(A_{c}\right)=0.0132 \mathrm{~m}^{2}
$$

According to the verification certificate of steel tap, the maximum error of indication $\Delta= \pm 0.001$ m. Therefore

$$
u(L)=u(W)=0.001 / \sqrt{3}=0.00058 \mathrm{~m}
$$

The measurement uncertainty components of $A_{\mathrm{c}}$ are shown in Tab.4.

Tab. 4 measurement uncertainty components of $A_{\mathrm{c}}$

\begin{tabular}{c|c|c|c|c|c}
\hline $\begin{array}{c}\text { input } \\
\text { quantity }\end{array}$ & $\begin{array}{c}\text { estimated } \\
\text { value }\end{array}$ & $\begin{array}{c}\text { standard } \\
\text { uncertainty }\end{array}$ & $\begin{array}{c}\text { distribution } \\
\text { type }\end{array}$ & $\begin{array}{c}\text { transform } \\
\text { coefficent }\end{array}$ & $\begin{array}{c}\text { uncertainty } \\
\text { components }\end{array}$ \\
\hline$A_{c}\left[\mathrm{~m}^{2}\right]$ & 1.928 & 0.0132 & normal & 1.000 & 0.00132 \\
\hline$L[\mathrm{~m}]$ & 1.631 & 0.00058 & rectangular & 1.000 & 0.00058 \\
\hline$W[\mathrm{~m}]$ & 1.182 & 0.00058 & rectangular & 1.000 & 0.00058 \\
\hline
\end{tabular}

Standard uncertainty of $A_{\mathrm{c}}$ is

$$
u_{A_{c}}=\sqrt{u^{2}\left(A_{c}\right)+u^{2}(L)+u^{2}(W)}=0.0132 \mathrm{~m}^{2}
$$

Relative standard uncertainty of $A_{\mathrm{c}}$ is shown in Eq.8.

$$
u_{r e l}\left(A_{c}\right)=u_{A_{c}} / A_{c}=0.69 \%
$$

The measurement standard uncertainty of temperature rise $\Delta t$. Transform coefficients related to $\Delta t$ are computed as Eq.9 and Eq. 10 .

$$
\begin{aligned}
& c_{t_{e}}=\partial(\Delta t) / \partial\left(t_{e}\right)=1 \\
& c_{t_{b}}=\partial(\Delta t) / \partial\left(t_{b}\right)=-1
\end{aligned}
$$

Measurement uncertainty of $t_{\mathrm{e}}$ and $t_{\mathrm{b}}$ comes from measurement error of PT100. According to technical specification of PT100, their expanded uncertainty are $\pm 0.09^{\circ} \mathrm{C}, k=2$. Therefore 


$$
u\left(t_{b}\right)=u\left(t_{e}\right)=0.09 / 2=0.045^{\circ} \mathrm{C}
$$

According to transform coefficient, measurement uncertainty components of temperature rise $\Delta t$ are shown in Tab.5.

Tab. 5 measurement uncertainty components of temperature rise $\Delta t$

\begin{tabular}{c|c|c|c|c|c}
\hline $\begin{array}{c}\text { input } \\
\text { quantity }\end{array}$ & $\begin{array}{c}\text { estimated } \\
\text { value }\end{array}$ & $\begin{array}{c}\text { standard } \\
\text { uncertainty }\end{array}$ & $\begin{array}{c}\text { distribution } \\
\text { type }\end{array}$ & $\begin{array}{c}\text { transform } \\
\text { coefficent }\end{array}$ & $\begin{array}{c}\text { uncertainty } \\
\text { components }\end{array}$ \\
\hline$t_{\mathrm{e}}$ & $57.76^{\circ} \mathrm{C}$ & $0.045^{\circ} \mathrm{C}$ & rectangular & 1.000 & $0.045^{\circ} \mathrm{C}$ \\
\hline$t_{\mathrm{b}}$ & $19.96^{\circ} \mathrm{C}$ & $0.045^{\circ} \mathrm{C}$ & rectangular & -1.000 & $0.045^{\circ} \mathrm{C}$ \\
\hline
\end{tabular}

Standard uncertainty of $\Delta t$ is as follows.

$$
u_{\Delta t}=\sqrt{c_{t_{e}}^{2} u\left(t_{e}\right)^{2}+c_{t_{b}}^{2} u\left(t_{b}\right)^{2}}=0.064^{\circ} \mathrm{C}
$$

Relative standard uncertainty of $\Delta t$ is shown in Eq. 11.

$$
u_{r e l}(\Delta t)=\frac{u_{\Delta t}}{\Delta t}=\frac{0.064}{37.8}=0.17 \%
$$

The measurement standard uncertainty of solar irradiance $\boldsymbol{H}$. The measurement uncertainty of solar irradiance $H$ mainly comes from uncertainty of total radiation meter. The uncertainty of total radiation meter can be estimated according to nonlinear error and temperature sensitivity ${ }^{[5]}$. The other method is to ignore the nonlinear error of total radiation meter and measurement values of daily solar irradiance is taken as a uniform distribution in reading $\pm 1.5 \%$ interval ${ }^{[6]}$. According to verification certificate of total radiation meter, its maximum permission error is $2.5 \%$. For rectangular uniform distribution, $k=\sqrt{3}$.

$$
u_{\text {rel }}(H)=2.5 \% / \sqrt{3} \approx 1.4 \%
$$

Expand uncertainty of daily useful energy. The measurement standard uncertainty components of daily useful energy $Q_{\mathrm{s}}$ are shown in Tab.6.

According to Eq.2, the measurement standard uncertainty of daily useful energy $Q_{\mathrm{s}}$ can be calculated as follows.

$$
u_{c}\left(Q_{s}\right)=1.59 \%
$$

Suppose $k=2$, the expanded uncertainty of daily useful energy $U(Q s)=2 * 1.59 \% \approx 3.2 \%$ 。

\section{Summary}

The paper designed and realized a movable thermal performance test system for domestic solar water heating system based LabVIEW. This test system satisfies the requirements of GB/T18708-2002. It can realize many functions such as automatic judge for test conditions of test items and data acquisition, process. The relative expanded measurement uncertainty of daily useful energy is $3.2 \%$.

Tab. 6 measurement uncertainty components of daily useful energy $Q_{\mathrm{s}}$

\begin{tabular}{c|c|c|c|c|c}
\hline quantity & $\begin{array}{c}\text { estimated } \\
\text { value }\end{array}$ & $\begin{array}{c}\text { standard } \\
\text { uncertainty }\end{array}$ & $\begin{array}{c}\text { distribution } \\
\text { type }\end{array}$ & $\begin{array}{c}\text { transform } \\
\text { coefficent }\end{array}$ & $\begin{array}{c}\text { uncertainty } \\
\text { components }\end{array}$ \\
\hline$m$ & 110.50 & $0.25[\mathrm{~kg}]$ & $0.23 \%$ & 1.00 & $0.23 \%$ \\
\hline$A_{\mathrm{c}}$ & 1.928 & $0.0132\left[\mathrm{~m}^{2}\right]$ & $0.69 \%$ & 1.00 & $0.69 \%$ \\
\hline$\triangle t$ & 37.80 & $0.064\left[{ }^{\circ} \mathrm{C}\right]$ & $0.17 \%$ & 1.00 & $0.17 \%$ \\
\hline$H$ & 19.045 & $-—$ & $1.4 \%$ & 1.00 & $1.4 \%$ \\
\hline
\end{tabular}




\section{Acknowledgement}

The paper is funded by Public Welfare Industry Special Scientific Research Projects for Quality Inspection, General Administration of Quality Supervision, Inspection and Quarantine of the People's Republic of China（No. 2008424349）

\section{References}

[1] He Tao, Zhang Lei, Zhang Xingyu. Introduction to detection of solar water heater in China. Science and Technology in Construction,2008,(3):21-23.

[2] HUANG Jinbao,PU Shaoxuan,GAO Wenfeng. Analysis on the Effect of Heat Exchangers on Thermal Performance of the Flat Plate Solar Water Heaters. Journal of Qiannan Normal College for Nationalities,2008,3:13-16

[3] Wang Haiming,Hu Jinlong. Design of High-speed data acquisition board based on PCI bus. Computer Measurement \& Control, 2012,20 (12) :3393-3396.

[4] SHEN Xiao-yan,LIN Jie-jun,LI Jia-fu,etc.. Evaluation and Error Analysis of Ultra-precision Two-dimensional Measuring and Positioning System Instrument Technique and Sensor, 2013(6):131-134.

[5]Chen Yuwu,Ma Guangbo,Liu Lei. The measurement uncertainty evaluation for daily useful energy and averge heat loss factor of domestic solar water heating system. Proceedings of 2011 annual meeting and peak forum of China's solar energy heat utilization industry ,2011,183-186

[6] Cheng Xiangwu ,Xie Jian ,Chen Tingjin,etc.. Evaluation of uncertainty in measurement solar water heater. Acta energiae solaris sinica, 2005,26(6):847-852 